\title{
Immune Modulation in Pediatric Sepsis
}

\author{
Mark W. Hall ${ }^{1,2}$ \\ ${ }^{1}$ Division of Critical Care Medicine, Nationwide Children's Hospital, \\ Columbus, Ohio, United States \\ 2 The Research Institute at Nationwide Children's Hospital, Columbus, \\ Ohio, United States
}

\begin{abstract}
Address for correspondence Mark W. Hall, MD, Division of Critical Care Medicine, Nationwide Children's Hospital, 700 Children's Drive, Columbus, $\mathrm{OH} 43205$, United States

(e-mail: mark.hall@nationwidechildrens.org).
\end{abstract}

\begin{abstract}
Keywords

- immune

- modulation

- pediatric

- sepsis

- HLA-DR

- TNF $\alpha$

The initial host immune response to sepsis in children is characterized by a proinflammatory surge that can be associated with fever, capillary leak, and organ dysfunction. There is, however, a concurrent anti-inflammatory response that results in hyporesponsiveness of innate and adaptive immune cells. When severe, this response is termed immunoparalysis and is known to be associated with prolonged organ dysfunction, increased risk for nosocomial infection, and death in septic adults and children. Sepsis-induced immune suppression can be defined in the laboratory by reduced whole blood ex vivo-stimulated cytokine production capacities, reduced expression of human leukocyte antigen (HLA)-DR on circulating monocytes, and reduced absolute cell counts. While anti-inflammatory therapies have largely been unsuccessful at improving outcomes from adult and pediatric sepsis, the use of immunostimulatory therapies such as granulocyte macrophage colony-stimulating factor (GM-CSF) in patients with sepsis-induced immunoparalysis shows promise. A greater understanding of the risk factors for immunoparalysis along with the development and execution of immunophenotype-specific clinical trials of strategies to optimize innate and adaptive immune function are needed to further improve outcomes in septic children.
\end{abstract}

\section{Introduction}

The proinflammatory response to infection is typically responsible for the classical signs and symptoms of sepsis such as fever, tachycardia, tachypnea, capillary leak, and organ dysfunction. This element of the host response has been targeted in numerous clinical trials in septic adults, in which anti-inflammatory therapies were employed in an effort to ameliorate the proinflammatory surge. The failure of most of these trials to improve outcomes led to the investigation of the counter-regulatory immune response to sepsis. In the last two decades, multiple investigators have identified an overly robust compensatory anti-inflammatory response to sepsis in some patients. This state, termed "immunoparalysis," has been associated with adverse outcomes including increased risks for nosocomial infection, prolonged organ dysfunction, and death. In this review, we will identify elements of the pro- and anti-inflammatory responses to pediatric sepsis, approaches to monitoring the immune response in septic children, and potential strategies for immunomodulation in pediatric sepsis with a goal of restoring immunologic balance.

\section{Host Response to Sepsis}

The production of proinflammatory cytokines and chemokines, when localized to infected tissues, makes the local environment more favorable in fighting infection. When these mediators spill over into the systemic circulation; however, they are responsible for the signs and symptoms of sepsis. The pathophysiologic features of acute sepsis are therefore largely attributable to the host's innate immune response to the offending pathogen. The innate immune system includes leukocytes such as received

October 30, 2018

accepted

November 2, 2018

published online

January 2, 2019
Issue Theme Advances in Pediatric Septic Shock; Guest Editor: E. Scott Halstead, MD, PhD.
Copyright (c) 2019 by Georg Thieme Verlag KG, Stuttgart · New York
DOI https://doi.org/ 10.1055/s-0038-1676607. ISSN 2146-4618. 
neutrophils, dendritic cells, monocytes, and macrophages. These cells broadly recognize and are activated by pathogenassociated molecular patterns (PAMP), such as lipopolysaccharide (LPS) though the ligation of constitutively expressed cell surface receptors. The best described of these are the toll-like receptors $\left(\mathrm{TLR}^{1}\right)$. This family of PAMP receptors includes those that can recognize a wide variety of molecules that are expressed by pathogens but not human cells. Upon activation, innate immune cells can ingest pathogens and kill them through enzymatic action or exposure to reactive oxygen species. Innate immune cells then digest the pathogen's proteins into antigenic peptides that are then loaded onto class II major histocompatibility complex (MHC) molecules, such as human leukocyte antigen (HLA)-DR. These antigens can then be presented to lymphocytes, members of the adaptive immune system. Finally, activated innate immune cells make proinflammatory cytokines which modulate the local environment to promote clearance of infection, along with chemokines which serve to attract other leukocytes to the area along concentration gradients. The innate immune response does not require prior exposure to a pathogen and should be of the same magnitude with each exposure.

The adaptive immune system consists of $\mathrm{T}$ and $\mathrm{B}$ lymphocytes. These cells typically, though not always, require activation through interaction with an antigen-bearing innate immune cell. The response is highly antigen-specific and is of greater magnitude and rapidity with subsequent exposures to an antigen. Activated B cells develop into plasma cells which produce antibody. T cells can be divided, based on cell surface marker expression, into CD4+ helper T cell and CD8+ cytotoxic T cell populations. Cytotoxic T cells promote cellular killing through elaboration of lytic enzymes. Helper T cells produce cytokines that modulate and perpetuate the immune response. Naïve helper $\mathrm{T}$ cells can differentiate into one of many subtypes depending on the signals they receive from antigen-presenting cells and the cytokine milieu in which they are activated. $T$ helper $\left(\mathrm{T}_{\mathrm{H}}\right)-1$ cells are proinflammatory and produce cytokines including interferon (IFN)- $\gamma$ and interleukin (IL)-2. $\mathrm{T}_{\mathrm{H}} 2$ cells promote anti-inflammatory and autoimmune/allergic responses through ela-

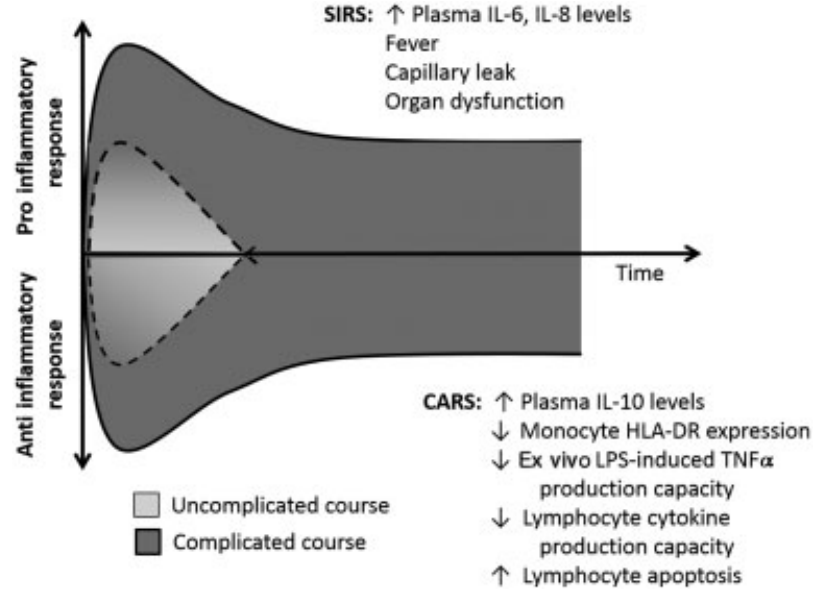

Fig. 1 Schematic of the dynamic inflammatory response to sepsis. CARS, compensatory anti-inflammatory response syndrome; SIRS, systemic inflammatory response syndrome.

boration of IL-10, IL-4, and IL-13. IL-17 that produces $\mathrm{T}_{\mathrm{H}} 17$ cells are potently proinflammatory while regulatory $\mathrm{T}$ cells $\left(\mathrm{T}_{\text {reg }}\right)$ are anti-inflammatory through production of IL-10, transforming growth factor (TGF) $\beta$, and through direct, cellcontact-mediated inhibition. Innate and adaptive immune cells, their actions, and mediators are listed in - Table 1.

\section{Immunologic Balance}

The systemic inflammatory response syndrome (SIRS) represents the clinical manifestation of the systemic proinflammatory response. The clinical phenotype of fever, tachycardia, tachypnea, and capillary leak is common to most inflammatory conditions including sepsis. However, every major biologic pathway has a counter-regulatory system. The compensatory anti-inflammatory response syndrome (CARS) is the "off switch" for the proinflammatory response (-Fig. 1). The CARS response has no clinical phenotype but is characterized by several important physiologic elements. First, within minutes to hours of the proinflammatory response becoming activated, innate and adaptive leukocytes can down-regulate intracellular signaling and become hyporesponsive to

Table 1 Immune effector cells, actions, and mediators

\begin{tabular}{|l|l|l|l|}
\hline & Cell type & Primary actions & Primary mediators \\
\hline Innate & Neutrophil & Phagocytosis, intracellular killing & $\begin{array}{l}\text { Reactive oxygen species, } \\
\text { lytic enzymes, TNF } \alpha\end{array}$ \\
\cline { 2 - 4 } & Monocyte & Phagocytosis, intracellular killing, antigen presentation & TNF $\alpha$, IL-1 $\beta$, IL-6, IL-8, IL-10 \\
\cline { 2 - 4 } & Macrophage & Phagocytosis, intracellular killing, antigen presentation & TNF $\alpha$, IL-1 $\beta$, IL-6, IL-8, IL-10 \\
\cline { 2 - 4 } & Dendritic cell & Phagocytosis, intracellular killing, antigen presentation & IFN $\alpha$, IL-12 \\
\cline { 2 - 4 } & Natural killer cell & Extracellular killing & Perforin, granzyme \\
\hline \multirow{5}{*}{ Adaptive } & CD4+ T cell & Cytokine production & $\mathrm{T}_{\mathrm{H}} 1, \mathrm{~T}_{\mathrm{H}} 17:$ IFN $\gamma$, IL-2, IL-17 \\
\cline { 2 - 4 } & & & $\mathrm{T}_{\mathrm{H}} 2, \mathrm{~T}_{\text {reg: IL-10, TGF } \beta, \text { IL-4, IL-13 }}$ \\
\cline { 2 - 4 } & CD8+ T cell & Extracellular killing & Perforin, granzyme \\
\cline { 2 - 4 } & B cell/plasma cell & Antibody production & Antibody \\
\hline
\end{tabular}

Abbreviations: IFN, interferon; IL, interleukin; TGF, transforming growth factor; $\mathrm{T}_{\mathrm{H}}$, T helper; TNF, tumor necrosis factor; $\mathrm{T}_{\text {reg }}$, regulatory $\mathrm{T}$ cell. 
stimulation. This period of quiescence serves to rein in the proinflammatory response and potentially avoid systemic spillover of cytokines. Second, leukocyte cell death can occur either as a result of their initial activation (e.g., neutrophils) or as the result of apoptosis (e.g., lymphocytes). Third, surviving innate and adaptive leukocytes can skew their cytokine production toward the production of anti-inflammatory mediators, such as IL-10. While it is likely beneficial to the host if brief and modest in magnitude, the CARS response can become pathological if severe and prolonged. In this setting, it is termed immunoparalysis and it represents an important form of acquired immune deficient which is very prevalent in the intensive care unit (ICU).

\section{Immunoparalysis in Sepsis}

The CARS response is quantifiable in the research laboratory and several approaches to the diagnosis of immunoparalysis have been undertaken in septic patients. The antigen presenting molecule HLA-DR should be expressed robustly on the surface of circulating monocytes. HLA-DR molecules are internalized as part of the CARS response and this can be quantified using flow cytometry. In a state of health, > 90\% of circulating monocytes should stain positive for HLA-DR, while a monocyte HLA-DR (mHLA-DR) expression level of $<30 \%$ is associated with increased risks for nosocomial infection and death. ${ }^{2-4}$ An alternate method allows for the quantitation of molecules of HLA-DR per cell, also using flow cytometry. A threshold of $<8,000$ molecules per cell has been used in adult studies to define immunoparalysis with $<5,000$ molecules per cell representing the most severe suppression. ${ }^{5,6}$ Thresholds of mHLA-DR expression that are associated with adverse outcomes from pediatric sepsis are less clear, with one recent study suggesting that the change in mHLA-DR expression over time may be more important that absolute thresholds. Manzoli et al found that mortality, in a 30-subject cohort of septic children, was associated with failure to increase mHLA-DR by at least 1,000 molecules per cell over the first week after sepsis onset. ${ }^{7}$

An alternative method to the diagnosis of immunoparalysis is the use of ex vivo stimulation of whole blood to identify subjects whose leukocytes are hyporesponsive. The whole blood ex vivo LPS-induced tumor necrosis factor (TNF)- $\alpha$ production capacity assay measures the ability of circulating innate immune cells to response to a new stimulus. In this assay, whole blood is added to a tube containing standardized LPS stimulation reagent and incubated for a period of time after which TNF $\alpha$ levels are measured in the supernatant. Healthy children's blood should produce large amounts of TNF $\alpha$ upon incubation with LPS. Marked reduction in the TNF $\alpha$ response is a feature of CARS with severe reductions being characteristic of immunoparalysis. It is important to note that the use of the TNF $\alpha$ response to evaluate innate immune function does not assign particular significance to TNF $\alpha$ itself or to the TLR4/CD14 pathway through which LPS signals. Rather, the TNF $\alpha$ response is used as a surrogate for the broader responsiveness of the innate immune cell by virtue of TNF $\alpha$ 's favorable kinetics and relative ease of measurement. In the most widely reported approach to this type of testing, a TNF $\alpha$ response less than approximately $200 \mathrm{pg} / \mathrm{mL}$ has been associated with increased risks for the development of nosocomial infection, prolonged organ dysfunction, and death in single- and multicenter cohorts of septic children. ${ }^{2,8,9}$ Thresholds of TNF $\alpha$ response that are associated with adverse outcomes may vary depending on the type of LPS used, blood volume used, incubation conditions, and the outcome being considered.

The adaptive immune system can also be affected as part of the CARS response. Lymphocyte apoptosis is common in the aftermath of sepsis, with peripheral lymphopenia and splenic lymphocyte depletion, having been associated with multiple organ dysfunction syndrome (MODS) and death in septic adults and children. ${ }^{10-12}$ Downregulation of lymphocyte responsiveness has similarly been associated with adverse outcomes from sepsis. Wong et al performed mRNA profiling on peripheral blood leukocytes early in the course of pediatric septic shock and evaluated expression of 100 genes corresponding to adaptive immunity and glucocorticoid receptor signaling. ${ }^{13}$ They identified two distinct patterns of gene expression or endotypes that were prevalent in the cohort, one with predominately suppressed gene expression and another with a substantially greater proportion of activated genes. Risks for mortality and prolonged MODS were significantly higher in children with the more suppressed endotype. Lymphocyte suppression at the protein level has also been shown to predict outcomes from sepsis. Adaptive immune testing can also utilize ex vivo stimulation as a tool for evaluating cellular responsiveness. Instead of using LPS as a stimulant, one must use a lymphocyte stimulant such as phytohemagglutinin (PHA) or antiCD3/anti-CD28 antibodies. Multiple cytokines have been evaluated as readouts from lymphocyte stimulation in this setting but reduced capacity to produce IFN $\gamma$ in response to ex vivo stimulation has been associated with the development of infectious complications, prolonged organ failure, and death in septic children and adults. ${ }^{9,11,14,15}$

The timing of innate and adaptive immune suppression is somewhat controversial in the field. Early work with innate immune function in septic adults suggested that very early suppression (e.g., days 1-2 of illness) was less predictive of adverse outcomes than were samples obtained later in the course (e.g., days 3-4). ${ }^{3,4}$ The first report of the TNF $\alpha$ response in children with MODS found increased risks for nosocomial infection and death in subjects whose immunoparalysis persisted beyond day 3 of MODS, though very early samples were rare in that cohort. ${ }^{2}$ Subsequent single- and multicenter studies have shown increased risks for prolonged organ dysfunction and death associated with severe suppression of the TNF $\alpha$ response and/or lymphocyte responsiveness as early as 1 to 2 days after sepsis onset. ${ }^{8,9}$ The significance of early versus late immunoparalysis as it relates to reversibility and outcomes remains unclear.

\section{History of Immunomodulation in Sepsis}

The 1980s and 1990s saw multiple phase II and III clinical trials of therapeutics designed to reduce the proinflammatory response to sepsis in adults. These included drugs to 
block or bind LPS, IL- $1 \beta$, TNF $\alpha$, and bradykinin as well as potent glucocorticoids, such as methylprednisolone or dexamethasone. ${ }^{16-23}$ These treatments consistently failed to improve outcomes and were occasionally associated with increased mortality. There were a few notable exceptions including the MONARCS trial in which a mortality benefit was seen in septic adults treated with anti-TNF $\alpha$ therapy but only if their initial plasma IL-6 levels were $>1,000 \mathrm{pg} / \mathrm{mL}^{24}$ Similarly, a secondary analysis of a large trial of IL-1 receptor antagonist suggested benefit in the subset of subjects who had hepatobiliary dysfunction and disseminated intravascular coagulation (chosen as a surrogate for macrophage activation syndrome [MAS]). ${ }^{25}$ Lastly, anecdotal evidence has suggested improved outcomes from the use of anti-IL-6 antibodies in children with severe cytokine release syndrome following chimeric antigen receptor (CAR) $\mathrm{T}$ cell therapy. ${ }^{26}$ Together, these data suggest that broad use of anti-inflammatory therapies likely has little place in acute sepsis management. Rather, there may be a role for the targeted use of selected anti-inflammatory drugs in septic patients with documented, severe hyperinflammation or in specific pathophysiologic states such as MAS.

\section{Immunostimulatory Therapies in Sepsis}

One possible reason for the failure of anti-inflammatory therapies in sepsis is that they may exacerbate or perpetuate sepsis-induced immune suppression. Immunoparalysis itself has become a target for immunomoduation in recent years, prompting a paradigm shift toward the use of immunostimulatory therapies in adults and children with severe immune suppression. The approaches were developed in response to the finding that immunoparalysis appears to be reversible. Fumeaux and Pugin were able to demonstrate restoration of HLA-DR expression in immunoparalyzed monocytes after ex vivo incubation with anti-IL-10 neutralizing antibodies. ${ }^{27}$ Since then several approaches to immunostimlation in septic patients have been evaluated (- Table 2). 2,6,28-39

The use of recombinant IFN $\gamma$ has been shown, in several small European case series, to be associated with improved mHLA-DR expression and TNF $\alpha$ response in septic adults with immunoparalysis. ${ }^{28,29}$ Interferon- $\gamma$ is currently being evaluated for the reversal of immunoparalysis (mHLA-DR $<30 \%$ ) in a multicenter, European randomized controlled trial (RCT) in septic adults (NCT03332225).

Granulocyte macrophage colony-stimulating factor (GMCSF) is a cytokine that is made by $\mathrm{T}_{\mathrm{H}} 1$ lymphocytes but is also available in recombinant form. GM-CSF was approved by the Food and Drug Administration (FDA) in 1991 for the restoration of bone marrow function following bone marrow transplantation and chemotherapy. In addition to its favorable side effect profile, GM-CSF represents an attractive candidate for the reversal of immunoparalysis in that it is capable of improving immune function in existing cells in addition to promoting the development of new cells of the monocyte and neutrophil lineages. Rosenbloom et al showed, in a small single-center RCT, that treatment with GM-CSF can result in improved mHLA-DR expression in septic adults, though enrollment was not limited to those with immunoparaly- sis. ${ }^{34}$ Meisel et al subsequently showed, in a 38-subject RCT of septic adults with proven, severe reduction in mHLA-DR expression that GM-CSF treatment was associated with prompt recovery of mHLA-DR expression and TNF $\alpha$ response. ${ }^{6}$ A similar single-center RCT was performed in septic children with MODS who demonstrated severe reduction in TNF $\alpha$ response $(<200 \mathrm{pg} / \mathrm{mL})^{2}{ }^{2}$ In this study, 14 subjects were randomized to a week of GM-CSF or standard therapy. Those receiving GM-CSF showed recovery of the TNF $\alpha$ response to normal levels by the end of the week of treatment, while the standard therapy arm had a much more modest response ( $\mathbf{F i g . 2}$ ). Interestingly, all of the subjects in the standard therapy arm developed a nosocomial infection while none were noted in the GM-CSF-treated group.

The adaptive immune system may also represent a target for immunostimulation in septic patients with immunoparalysis. While lymphocyte-specific colony stimulating factors are not available, several other approaches have shown promise in preclinical models. IL-7 inhibits lymphocyte apoptosis and enhances lymphocyte responsiveness in vitro. In murine studies, administration of recombinant IL-7 was associated with improved lymphocyte function and survival in a two-hit model of peritonitis and candida pneumonia. ${ }^{40}$ The programmed death (PD)-1 pathway represents another potential target for immunomodulatory therapy in sepsis. PD-1 is a coinhibitory molecule expressed by lymphocytes and binding by its ligands PD-L1 or PD-L2 on antigen presenting cells results in lymphocyte deactivation and/or apoptosis. Anti-PD-1 antibodies are FDA-approved as immunotherapy to promote lymphocyte responses against some forms of cancer. These have also been evaluated in murine models of sepsis, with improvements in innate and adaptive immune function and improved survival reported. ${ }^{41,42}$ At least one blocking antibody in the PD-1 family has been evaluated in human sepsis (NCT02576457) though results have not yet been reported. Interestingly, preclinical data suggest that combinatorial therapy with anti-PD-1 antibodies and recombinant IL-7 may more beneficial than either alone. ${ }^{39}$

\section{Unintended Immunomodulation}

While the prior section focused on intentional immunomodulation, it must be acknowledged that a great many therapies that are routinely employed in the care of children with sepsis have unintended immunologic effects, most of which are immunosuppressive. Red blood cell (RBC) transfusion, for example, may reduce leukocyte function as has been demonstrated in vitro and in septic children. ${ }^{43,44}$ The use of therapeutic hypothermia is known to reduce neutrophil function. ${ }^{45}$ Many of the drugs in the ICU (intensive care unit) pharmacopeia are, in fact, immunomodulators ( - Table 3 ). The clinical relevance of the individual and net effects of these therapies on immune function remains unknown and represents a crucial gap in our understanding of ICU pathophysiology. In addition to identifying treating patients with immunoparalysis, there is a great need for the development and testing of immunefriendly treatment regimens that may prevent the development of immunoparalysis in some cases. 
Table 2 Summary of clinical trials of immunostimulation for treatment of sepsis-induced immune suppression

\begin{tabular}{|c|c|c|c|c|}
\hline Study & Design & Population & $n$ & Findings \\
\hline \multicolumn{5}{|l|}{ IFN-y } \\
\hline Döcke, 1997 & Case series & $\begin{array}{l}\text { Septic adults with low } \\
\text { mHLA-DR expression }\end{array}$ & 9 & $\begin{array}{l}\uparrow \text { mHLA-DR expression and TNF } \alpha \text { production } \\
\text { capacity after treatment }\end{array}$ \\
\hline Delsing, 2014 & Case series & $\begin{array}{l}\text { Adults with severe } \\
\text { invasive fungal sepsis }\end{array}$ & 8 & $\begin{array}{l}\text { Increased mHLA-DR expression and enhanced } \\
\text { antifungal proinflammatory cytokine } \\
\text { production }\end{array}$ \\
\hline \multicolumn{5}{|l|}{ GM-CSF } \\
\hline Bilgin, 2001 & $\mathrm{RCT}$ & Septic neonates with neutropenia & 60 & $\downarrow$ Mortality in treatment group \\
\hline $\begin{array}{l}\text { Drossou-Agakidou, } \\
2002\end{array}$ & $\mathrm{RCT}$ & Septic neonates & 56 & $\begin{array}{l}\uparrow \mathrm{mHLA}-\mathrm{DR} \text { in GM-CSF treated group } \\
\text { compared with G-CSF or placebo }\end{array}$ \\
\hline Presneill, 2002 & $\mathrm{RCT}$ & $\begin{array}{l}\text { Septic adults with } \\
\text { pulmonary dysfunction }\end{array}$ & 18 & $\begin{array}{l}\uparrow \text { Neutrophil function and improved } \\
\text { oxygenation in treated group }\end{array}$ \\
\hline Nierhaus, 2003 & Case series & $\begin{array}{l}\text { Septic adults with low } \\
\text { mHLA-DR expression }\end{array}$ & 9 & $\begin{array}{l}\uparrow \text { mHLA-DR expression and TNF- } \alpha \text { production } \\
\text { capacity after treatment }\end{array}$ \\
\hline Rosenbloom, 2005 & $\mathrm{RCT}$ & Septic adults & 33 & $\begin{array}{l}\uparrow \text { mHLA-DR expression and faster resolution } \\
\text { of infection in treated group }\end{array}$ \\
\hline Orozco, 2006 & $\mathrm{RCT}$ & Adults with abdominal sepsis & 58 & $\begin{array}{l}\downarrow \text { Hospital stay and } \downarrow \text { infectious } \\
\text { complications in treated group }\end{array}$ \\
\hline Meisel, 2009 & RCT & Septic adults with low mHLA-DR & 38 & $\begin{array}{l}\uparrow \text { mHLA-DR expression and } \downarrow \text { durations of } \\
\text { mechanical ventilation and ICU stay in } \\
\text { treated group }\end{array}$ \\
\hline Hall, 2011 & RCT & $\begin{array}{l}\text { Children with MODS and low } \\
\text { TNF } \alpha \text { production capacity }\end{array}$ & 14 & $\begin{array}{l}\text { Enhanced TNF } \alpha \text { production capacity and } \\
\text { lower incidence of nosocomial infection in } \\
\text { treated group. }\end{array}$ \\
\hline Paine, 2012 & $\mathrm{RCT}$ & Adults with ALI/ARDS & 132 & No difference in ventilator-free days \\
\hline \multicolumn{5}{|l|}{ IL-7 } \\
\hline Venet, 2012 & $\begin{array}{l}\text { Ex vivo } \\
\text { (cell culture) }\end{array}$ & Adults with septic shock & 10 & $\begin{array}{l}\uparrow \text { Lymphocyte proliferation and INF- } \gamma \\
\text { production }\end{array}$ \\
\hline Thampy, 2018 & $\begin{array}{l}\text { Ex vivo } \\
\text { (cell culture) }\end{array}$ & Septic adults & 26 & $\uparrow$ IFN- $y$ production \\
\hline \multicolumn{5}{|l|}{ Anti-PD-1 antibodies } \\
\hline Chang, 2014 & $\begin{array}{l}\text { Ex vivo } \\
\text { (cell culture) }\end{array}$ & Septic adults & 19 & $\begin{array}{l}\uparrow \text { IFN- } y \text { production and decreased lymphocyte } \\
\text { apoptosis }\end{array}$ \\
\hline Thampy, 2018 & $\begin{array}{l}\text { Ex vivo } \\
\text { (cell culture) }\end{array}$ & Septic adults & 26 & $\uparrow I F N-\gamma$ production \\
\hline
\end{tabular}

Abbreviations: ALI, acute lung injury; ARDS, acute respiratory distress syndrome; G-CSF, granulocyte colony stimulating factor; GM-CSF, granulocyte macrophage colony stimulating factor; ICU, intensive care unit; IFN- - , interferon gamma; IL, interleukin; mHLA-DR, monocyte human leukocyte antigen-DR expression; MODS, multiple organ dysfunction syndrome; PD, programed death; RCT, randomized controlled trial; TNF, tumor necrosis factor.

Note: Up arrows indicate increase, down arrows indicate decrease.

\section{Summary and Future Directions}

The immune response to sepsis is highly dynamic and has both pro- and anti-inflammatory components. The presence of high levels of systemic inflammation, with accompanying symptoms of SIRS, doesnot rule out the presence of a compensatory anti-inflammatory response which may in itself be pathologic. Early attempts at immunomodulation in sepsis were likely flawed due to their singular focus on reduction of the proinflammatory response without measuring resultant effects on immune cell function. While some patients with severe inflammation may benefit from anti-inflammatory therapies, it is likely that these therapies should be carefully targeted, of short duration, and accompanied by immune function monitoring. Conversely, many patients with sepsis may benefit from immune stimulation to reverse immunoparalysis and restore the ability to clear infection, survey for and combat new infection, and remodel injured tissues. There are several therapies that show promise for the reversal of innate immune suppression in sepsis of which GM-CSF has the largest body of evidence to date. Strategies that target restoration of lymphocyte function in sepsis are under development as well. It is likely that a combinatorial approach, driven by prospective immune function testing of the innate and adaptive arms of the immune system, will be needed in some patients to achieve 


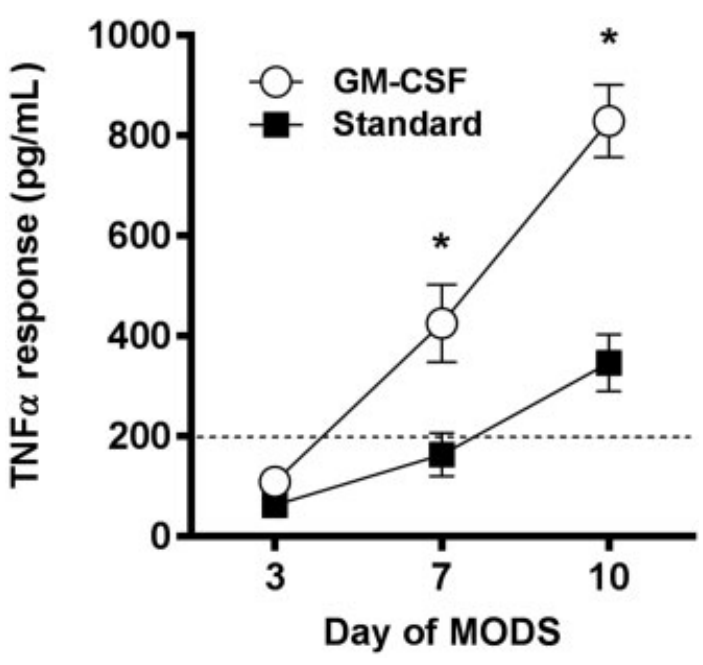

Fig. 2 Reversal of pediatric sepsis-induced immunoparalysis using GM-CSF. Treatment with GM-CSF (open circles) was associated with more rapid and more robust restoration of the TNF $\alpha$ response compared with standard therapy (dark squares) in a small RCT in children with sepsis-induced MODS and immunoparalysis ( $n-14$; adapted from Hall, 20112). $p<0.05$. Note: TNF $\alpha$ response values from healthy children are approximately $1,000 \mathrm{pg} / \mathrm{mL}$. GM-CSF, granulocyte macrophage colony stimulating factor; MODS, multiple organ dysfunction syndrome.

Table 3 Unintended immunomodulatory effects of common ICU therapies

\begin{tabular}{|c|c|c|}
\hline & $\begin{array}{l}\text { Immune } \\
\text { effect }\end{array}$ & Putative mechanisms \\
\hline \multirow[t]{2}{*}{ RBC transfusion } & $\uparrow$ & $\begin{array}{l}\text { Allogeneic transfusion } \\
\text { reactions, passenger } \\
\text { leukocytes } 46\end{array}$ \\
\hline & $\downarrow$ & $\begin{array}{l}\text { Inhibition of cytokine } \\
\text { production } 46\end{array}$ \\
\hline \multirow[t]{2}{*}{$\begin{array}{l}\text { Antibacterial } \\
\text { agents }\end{array}$} & $\uparrow$ & $\begin{array}{l}\text { Release of PAMPs upon } \\
\text { pathogen death } 47\end{array}$ \\
\hline & $\downarrow$ & $\begin{array}{l}\text { Bone marrow suppression, } \\
\text { inhibition of cytokine } \\
\text { production } 48\end{array}$ \\
\hline Benzodiazepines & $\downarrow$ & $\begin{array}{l}\text { Cortisol induction, direct } \\
\text { leukocyte inhibition } 49\end{array}$ \\
\hline \multirow{2}{*}{$\begin{array}{l}\text { Epinephrine/ } \\
\text { norepinephrine }\end{array}$} & $\uparrow$ & Stimulation of $\alpha$ receptors ${ }^{50}$ \\
\hline & $\downarrow$ & Stimulation of $\beta$ receptors ${ }^{50}$ \\
\hline Dopamine & $\downarrow$ & $\begin{array}{l}\text { Inhibition of prolactin } \\
\text { secretion }^{51}\end{array}$ \\
\hline Furosemide & $\downarrow$ & $\begin{array}{l}\text { Inhibition of cytokine } \\
\text { production } 52\end{array}$ \\
\hline Insulin & $\downarrow$ & $\begin{array}{l}\text { Inhibition of proinflammatory } \\
\text { signaling pathways } 5^{53}\end{array}$ \\
\hline Opiates & $\downarrow$ & $\begin{array}{l}\text { Inhibition of cytokine } \\
\text { production, induction of } \\
\text { apoptosis }\end{array}$ \\
\hline
\end{tabular}

Abbreviations: ICU, intensive care unit; PAMPs, pathogen-associated molecular patterns; RBC, red blood cell.

Note: Up arrows indicate increased inflammatory response, down arrows indicate decreased inflammatory response. prompt and lasting restoration of immune function. Lastly, though the largest body of data on the TNF $\alpha$ response in critical illness comes from the pediatric population, the vast majority of immunomodulation data can be found in the adult literature. The development of multicenter, prospective immune function monitoring, and modulation studies in septic children will be essential to safely bring these therapies into the pediatric ICU and improve outcomes in this vulnerable population.

\section{Conflict of Interest \\ None declared.}

\section{References}

1 Uematsu S, Akira S. Toll-like receptors (TLRs) and their ligands. Handb Exp Pharmacol 2008;(183):1-20

2 Hall MW, Knatz NL, Vetterly C, et al. Immunoparalysis and nosocomial infection in children with multiple organ dysfunction syndrome. Intensive Care Med 2011;37(03):525-532

3 Volk HD, Reinke P, Krausch D, et al. Monocyte deactivationrationale for a new therapeutic strategy in sepsis. Intensive Care Med 1996;22(Suppl 4):S474-S481

4 Monneret G, Lepape A, Voirin N, et al. Persisting low monocyte human leukocyte antigen-DR expression predicts mortality in septic shock. Intensive Care Med 2006;32(08):1175-1183

5 Döcke WD, Höflich C, Davis KA, et al. Monitoring temporary immunodepression by flow cytometric measurement of monocytic HLA-DR expression: a multicenter standardized study. Clin Chem 2005;51(12):2341-2347

6 Meisel C, Schefold JC, Pschowski R, et al. Granulocyte-macrophage colony-stimulating factor to reverse sepsis-associated immunosuppression: a double-blind, randomized, placebo-controlled multicenter trial. Am J Respir Crit Care Med 2009;180(07):640-648

7 Manzoli TF, Troster EJ, Ferranti JF, Sales MM. Prolonged suppression of monocytic human leukocyte antigen-DR expression correlates with mortality in pediatric septic patients in a pediatric tertiary intensive care unit. J Crit Care 2016;33:84-89

8 Hall MW, Geyer SM, Guo CY, et al; Pediatric Acute Lung Injury and Sepsis Investigators (PALISI) Network PICFlu Study Investigators. Innate immune function and mortality in critically ill children with influenza: a multicenter study. Crit Care Med 2013;41(01): 224-236

9 Muszynski JA, Nofziger R, Moore-Clingenpeel M, et al. Early immune function and duration of organ dysfunction in critically III children with sepsis. Am J Respir Crit Care Med 2018;198(03): 361-369

10 Felmet KA, Hall MW, Clark RS, Jaffe R, Carcillo JA. Prolonged lymphopenia, lymphoid depletion, and hypoprolactinemia in children with nosocomial sepsis and multiple organ failure. J Immunol 2005;174(06):3765-3772

11 Boomer JS, To K, Chang KC, et al. Immunosuppression in patients who die of sepsis and multiple organ failure. JAMA 2011;306(23): 2594-2605

12 Hotchkiss RS, Tinsley KW, Swanson PE, et al. Sepsis-induced apoptosis causes progressive profound depletion of $\mathrm{B}$ and CD4+ T lymphocytes in humans. J Immunol 2001;166(11): 6952-6963

13 Wong HR, Cvijanovich NZ, Anas N, et al. Developing a clinically feasible personalized medicine approach to pediatric septic shock. Am J Respir Crit Care Med 2015;191(03):309-315

14 Muszynski JA, Nofziger R, Greathouse K, et al. Early adaptive immune suppression in children with septic shock: a prospective observational study. Crit Care 2014;18(04):R145 
15 Boomer JS, Shuherk-Shaffer J, Hotchkiss RS, Green JM. A prospective analysis of lymphocyte phenotype and function over the course of acute sepsis. Crit Care 2012;16(03):R112

16 Calandra T, Glauser MP, Schellekens J, Verhoef J. Treatment of gram-negative septic shock with human IgG antibody to Escherichia coli J5: a prospective, double-blind, randomized trial. J Infect Dis 1988;158(02):312-319

17 McCloskey RV, Straube RC, Sanders C, Smith SM, Smith CR; CHESS Trial Study Group. Treatment of septic shock with human monoclonal antibody HA-1A. A randomized, double-blind, placebocontrolled trial. Ann Intern Med 1994;121(01):1-5

18 Fisher CJ Jr, Dhainaut JF, Opal SM, et al. Recombinant human interleukin 1 receptor antagonist in the treatment of patients with sepsis syndrome. Results from a randomized, double-blind, placebo-controlled trial. Phase III rhIL-1ra Sepsis Syndrome Study Group. JAMA 1994;271(23):1836-1843

19 Opal SM, Fisher CJ Jr., Dhainaut JF, et al. Confirmatory interleukin1 receptor antagonist trial in severe sepsis: a phase III, randomized, double-blind, placebo-controlled, multicenter trial. The Interleukin-1 Receptor Antagonist Sepsis Investigator Group. Crit Care Med 1997;25(07):1115-1124

20 Fisher CJ Jr, Agosti JM, Opal SM, et al; The Soluble TNF Receptor Sepsis Study Group. Treatment of septic shock with the tumor necrosis factor receptor:Fc fusion protein. N Engl J Med 1996;334 (26): $1697-1702$

21 Abraham E, Anzueto A, Gutierrez G, et al; NORASEPT II Study Group. Double-blind randomised controlled trial of monoclonal antibody to human tumour necrosis factor in treatment of septic shock. Lancet 1998;351(9107):929-933

22 Fein AM, Bernard GR, Criner GJ, et al. Treatment of severe systemic inflammatory response syndrome and sepsis with a novel bradykinin antagonist, deltibant (CP-0127). Results of a randomized, double-blind, placebo-controlled trial. CP-0127 SIRS and sepsis study group. JAMA 1997;277(06):482-487

23 Sprung CL, Caralis PV, Marcial EH, et al. The effects of high-dose corticosteroids in patients with septic shock. A prospective, controlled study. N Engl J Med 1984;311(18):1137-1143

24 Panacek EA, Marshall JC, Albertson TE, et al. Efficacy and safety of the monoclonal anti-tumor necrosis factor antibody F(ab')2 fragment afelimomab in patients with severe sepsis and elevated interleukin-6 levels. Crit Care Med 2004;32(11):2173-2182

25 Shakoory B, Carcillo JA, Chatham WW, et al. Interleukin-1 receptor blockade is associated with reduced mortality in sepsis patients with features of macrophage activation syndrome: reanalysis of a prior phase III trial. Crit Care Med 2016;44(02): 275-281

26 Teachey DT, Rheingold SR, Maude SL, et al. Cytokine release syndrome after blinatumomab treatment related to abnormal macrophage activation and ameliorated with cytokine-directed therapy. Blood 2013;121(26):5154-5157

27 Fumeaux T, Pugin J. Role of interleukin-10 in the intracellular sequestration of human leukocyte antigen-DR in monocytes during septic shock. Am J Respir Crit Care Med 2002;166(11): 1475-1482

28 Döcke WD, Randow F, Syrbe U, et al. Monocyte deactivation in septic patients: restoration by IFN-gamma treatment. Nat Med 1997;3(06):678-681

29 Delsing CE, Gresnigt MS, Leentjens J, et al. Interferon-gamma as adjunctive immunotherapy for invasive fungal infections: a case series. BMC Infect Dis 2014;14:166

30 Bilgin K, Yaramiş A, Haspolat K, Taş MA, Günbey S, Derman O. A randomized trial of granulocyte-macrophage colony-stimulating factor in neonates with sepsis and neutropenia. Pediatrics 2001; 107(01):36-41

31 Drossou-Agakidou V, Kanakoudi-Tsakalidou F, Sarafidis K, et al. In vivo effect of rhGM-CSF And rhG-CSF on monocyte HLA-DR expression of septic neonates. Cytokine 2002;18(05):260-265
32 Presneill JJ, Harris T, Stewart AG, Cade JF, Wilson JW. A randomized phase II trial of granulocyte-macrophage colony-stimulating factor therapy in severe sepsis with respiratory dysfunction. Am J Respir Crit Care Med 2002;166(02):138-143

33 Nierhaus A, Montag B, Timmler N, et al. Reversal of immunoparalysis by recombinant human granulocyte-macrophage colonystimulating factor in patients with severe sepsis. Intensive Care Med 2003;29(04):646-651

34 Rosenbloom AJ, Linden PK, Dorrance A, Penkosky N, CohenMelamed MH, Pinsky MR. Effect of granulocyte-monocyte colony-stimulating factor therapy on leukocyte function and clearance of serious infection in nonneutropenic patients. Chest 2005; 127(06):2139-2150

35 Orozco H, Arch J, Medina-Franco H, et al. Molgramostim (GM-CSF) associated with antibiotic treatment in nontraumatic abdominal sepsis: a randomized, double-blind, placebo-controlled clinical trial. Arch Surg 2006;141(02):150-153, discussion 154

36 Paine R III, Standiford TJ, Dechert RE, et al. A randomized trial of recombinant human granulocyte-macrophage colony stimulating factor for patients with acute lung injury. Crit Care Med 2012; 40(01):90-97

37 Venet F, Foray AP, Villars-Méchin A, et al. IL-7 restores lymphocyte functions in septic patients. J Immunol 2012;189(10):5073-5081

38 Thampy LK, Remy KE, Walton AH, et al. Restoration of T Cell function in multi-drug resistant bacterial sepsis after interleukin7, anti-PD-L1, and OX-40 administration. PLoS One 2018;13(06): e0199497

39 Chang K, Svabek C, Vazquez-Guillamet C, et al. Targeting the programmed cell death 1: programmed cell death ligand 1 pathway reverses $\mathrm{T}$ cell exhaustion in patients with sepsis. Crit Care 2014;18(01):R3

40 Unsinger J, Burnham CA, McDonough J, et al. Interleukin-7 ameliorates immune dysfunction and improves survival in a 2hit model of fungal sepsis. J Infect Dis 2012;206(04):606-616

41 Chang KC, Burnham CA, Compton SM, et al. Blockade of the negative co-stimulatory molecules PD- 1 and CTLA-4 improves survival in primary and secondary fungal sepsis. Crit Care 2013; 17(03):R85

42 Shindo Y, Unsinger J, Burnham CA, Green JM, Hotchkiss RS Interleukin-7 and anti-programmed cell death 1 antibody have differing effects to reverse sepsis-induced immunosuppression. Shock 2015;43(04):334-343

43 Muszynski J, Nateri J, Nicol K, Greathouse K, Hanson L, Hall M. Immunosuppressive effects of red blood cells on monocytes are related to both storage time and storage solution. Transfusion 2012;52(04):794-802

44 Muszynski JA, Frazier E, Nofziger R, et al. Pediatric Critical Care Blood Research Network (Blood Net) subgroup of the Pediatric Acute Lung Injury and Sepsis Investigators (PALISI). Red blood cell transfusion and immune function in critically ill children: a prospective observational study. Transfusion 2015;55(04): 766-774

45 Hildebrand F, van Griensven M, Giannoudis P, et al. Impact of hypothermia on the immunologic response after trauma and elective surgery. Surg TechnolInt 2005;14:41-50

46 Muszynski JA, Spinella PC, Cholette JM, et al; Pediatric Critical Care Blood Research Network (Blood Net). Transfusion-related immunomodulation: review of the literature and implications for pediatric critical illness. Transfusion 2017;57(01):195-206

47 Labro MT. Antibacterial agents-phagocytes: new concepts for old in immunomodulation. Int J Antimicrob Agents 1998;10(01): 11-21

48 Tamaoki J, Kadota J, Takizawa H. Clinical implications of the immunomodulatory effects of macrolides. Am J Med 2004;117 (Suppl 9A):5S-11S

49 Zavala F. Benzodiazepines, anxiety and immunity. Pharmacol Ther 1997;75(03):199-216 
50 Stolk RF, van der Poll T, Angus DC, van der Hoeven JG, Pickkers P, Kox M. Potentially inadvertent immunomodulation: norepinephrine use in sepsis. Am J Respir Crit Care Med 2016;194(05):550-558

51 Yu-Lee LY. Molecular actions of prolactin in the immune system. Proc Soc Exp Biol Med 1997;215(01):35-52

52 Yuengsrigul A, Chin TW, Nussbaum E. Immunosuppressive and cytotoxic effects of furosemide on human peripheral blood mononuclear cells. Ann Allergy Asthma Immunol 1999;83(6,Pt 1):559-566
53 Dandona P, Aljada A, Mohanty P, et al. Insulin inhibits intranuclear nuclear factor kappaB and stimulates IkappaB in mononuclear cells in obese subjects: evidence for an anti-inflammatory effect? J Clin Endocrinol Metab 2001;86(07):3257-3265

54 Bhat RS, Bhaskaran M, Mongia A, Hitosugi N, Singhal PC. Morphine-induced macrophage apoptosis: oxidative stress and strategies for modulation. J Leukoc Biol 2004;75(06): $1131-1138$ 
